\title{
Studies on English Translation of Shijing in China: From Language to Culture Yan-Hua WANG ${ }^{1}$ and Pei-Xi HUANG, ${ }^{2,}$
}

${ }^{1}$ Shanghai Technical Institute of Electronics and Technology, Fudan University, Fengxian District, Shanghai, China

${ }^{2}$ College of foreign languages, Donghua University, Shanghai, China

${ }^{*}$ Corresponding author

Keywords: Shijing, English translation, Cultural consciousness.

\begin{abstract}
Studies on English translation of Shijing have undergone three phases in China. It begins with introductions of English versions and their translators as well as comparisons between them; the second phase features in the theoretical attempt of translational strategies. The first two phases stress more language or translation theories than cultures. The third is characterized by cross-cultural, interdisciplinary and multidimensional research on English translation of Shijing. Meanwhile, new translational theories and historical literature offer new perspectives for studies on English translation of Shijing, which enhances its cross-cultural research in the new era.
\end{abstract}

\section{Introduction}

English translation of Shijing can be dated back to the eighteenth century. It is believed that English translation of Shijing was initiated by Sir William Jones, a British orientalist and translator, who was interested in Chinese culture and attempted to translate some poems in Shijing into English.[1] His work marked the beginning of Shijing going into the English world and studies on it have been continuously carried on ever since. Compared with overseas research on the English translation of Shijing, its studies in China began much later. Recent literature reveals that most studies did not begin until 1980s. Chinese studies on English translation of Shijing can be divided into three phases: introduction of English versions and their translators in the first phrase, theoretical attempts in the second and cross-cultural, interdisciplinary and multidimensional studies in the third.

\section{BuddingStudies on Shijing Translation: Introduction and Comparison}

Studies on English translation of Chinese poetry started three decades ago. In the early period, the focus of researchers was mainly on introduction of English versions of Shijing and their translators.

\section{Introduction of English Versions of Shijing and Their Translators}

In China, Fan Cunzhong was among the earliest researchers who made historical exploration on English translations of Shijing. His monograph, Chinese Culture in Britain during the Period of Enlightenment (1993), de votes one chapter to an account of Sir William Jones' translating work and his English version of Qi Ao in Shijing.[1]The author investigated Sir William Jones' pioneering work including his spontaneous interest in Chinese poetry and immature understanding of Chinese culture. This book is generally considered as the beginning of cultural intercourse of 
Shijing between China and Britain. Besides, it is of great academic significance for its accurate and faithful historical records.

$\mathrm{Xu}$ Yuanchong, in his preface to The Book of Poetry(1993), the English version of Shijing,briefly compared the translated works of Shijing by James Legge, Ezra Pound and Arthur Waley. He introduced James Legge's metrical version of The Shi King published in 1876 and verbal version published in Hong Kong in the 1871. He introduced that Legge's version is "a scholarly rendition which reads unlike the simple and plain original."'[2] In 1891, two English versions of Shijing, translated by C.F.R. Allen and William Jennings respectively, were published. Xu commented that Allen's The Shih Ching (Classic of Poetry) published in 1891 "assumes the liberty to vary from the words and sense of the original, and his metrical version is more like adaptation than translation.' [2] He remarked that L. Cranmer-Byng's metrical version of Shih-King (the Book of Odes, 1906) is not so free in sense nor so regular in form as Allen's.[2] In 1913, Helen Waddell published her Lyrics from the Chinese which "omits a great deal in her version though she adds little or nothing" and "makes an organization of her own."'[2] Louis S. Hammond adopted "the close translation" by using "one syllable in English to represent one word in Chinese and at the same time preserve the original rhyme scheme in her translation."[2] Xu also mentioned Ezra Pound's free rendition of The Classic Anthology as Defined by Confucius with "abundant color, freshness and poignancy" despite its "extravagant errors" and Arthur Waley'srhymeless translation of The Book of Songs in which "one stressed English syllables represents one word in Chinese". [2] William Jones' version of Shijing, in Xu's opinion, is between "paraphrase" and "imitation". [3] By pointing out the merits and demerits of each version, Xu tried to produce a better one which can best keep the beauty of Shijing in its sound, form and meaning and convey Chinese culture to foreign readers. However, his research put more emphasis on translating techniques than cultural transference.

Classical Chinese Literature outside China (1994) introduces English translation of Shijing and dissemination in the west. It is pointed out that western scholars' interest in Shijing mainly covers three areas, i.e. its sociological studies, its aesthetic studies and studies on vernaculars of "feng", " $y a$ " and "song", followed by a very brief introduction of William Jones" work as well as his "literal translation" and "paraphrase".[4] This book, aimed at a panorama of translating and spreading classical Chinese literature outside China, offers a very little space for Shijing.

Another much appreciated book comes from Hu Xianyuan'sShijing: Songs from Ancient Chinese (1998). One chapter, entitled Translation and dissemination of Shijing in foreign Countries, gives an informative account of its translation and dissemination all over the world. The English part touches upon such important translators as Sir William Jones, James Legge, Herbert Giles, Arthur Waley, Ezra Pound and Bernhard Karlgren together with their life and translating work. The author made a few remarks to characterize each translator and his translation. James Legge's version is regarded as "accuracy", which has been and is still an authoritative version so far, Waley's as a model of "elegance" for its delicacy, vividness and refinement and a good combination of faithfulness, elegance and expressiveness. Karlgren's version of Shijing is lauded as a landmark masterpiece, an equal to Waley's, Giles' known for its readability, rhythmicity and gracefulness, Pound's rendition "distinctive" for its recreation. Yet Pound's misreading and misinterpreting endows this version with a special place in cultural communication between the east and the west.[5] Hu's informative book enables readers to get a good idea of Shijing's reception home and abroad throughout the history, but sadly it is not free from errors. For instance, the 
author mentioned Lionel Giles had rendered Shijing, but provided no reliable sources while the generally accepted biography of Lionel Giles denies it. Therefore, it is not very convincing. In addition, J. R. Hightower is recorded to have translated Shijing in this book but the fact is that he translatedHan Shih Wai Chuan: Han Ying's Illustrations of the Didactic Application of the Classic of Songs (1952), in which Han Ying quoted some lines from Shijing to support his arguments. But this is not a real English translation of Shijing.

\section{Dissemination of Shijingoutside China}

Along with the translation, the spreading and reception of Shijing has been another academic interest for researchers. Zhou Faxiang is one of the earliest researchers who made such studies. His paper, The Spread and Research on Shijing in the West (1993), made a relatively thorough introduction of Shijing in the western countries. It is composed of two parts. The first part dwells on the translating work of early missionaries, the stylistic turn from its religious-orientation to academic-orientation as well as sinologists' translating and researching work on Shijing and the second part is mainly on some focuses of western research, such as writing techniques, folkloristics, linguistics and the application of Parry-Lord Theory in translating and researching. The paper, brief as it is, has ignited numerous studies.[6] Similar research can be found in Shijing outside China (1993) and The Formation and Evolution of Studies on Shijing in the West (1996) reviewing foreign translations of Shijingand establishment of studies on Shijing in the west as a discipline respectively.[7,8] A brief history of renditions and reception of Shijing was found in Shan Qing's Transmission of Shijing to the West and Its Translation (1995).[9]

Foreign studies on Shijing are divided into three phases: beginning in the eighteenth century, further development in the nineteenth century and advanced research in the twentieth century.[10] In the beginning of translation studies on Shijing, considering general readers' ignorance of this field, researchers focused more on the introductory work than in-depth analysis, so that readers might get a good knowledge of translators and their translating work, the English versions as well as the transmission and reception of Shijing. As for studies on translators, much had been done about their life and their translation of Shijing; studies on English versions of Shjing are mainly concentrated on basic information of individual renderings such as the use of rhymes or free verses, times and publishing places of different translations while its transmission and reception primarily dwelt on the history of reception and progression of successive English versions.

\section{Further Development of Studies on English Translating of Shijing: Theoretical Exploration of Poetry Translation}

In the late 1990s, research on Shijing translation turned from factual account to theoretical attempt. Researchers endeavored to find out what had manipulated translators in their translating and what distinct translation theories had made poetry translations distinctive from other literary translations.

LüShuxiang pioneered theoretical exploration of Chinese poetry translation. His great work, A Comparative Study on English Translation of Old Gems (1948), was prefaced with his understanding of poetry translation.

"Considering the profundity of Chinese language and terseness of poetical diction, it is forgivably unavoidable for foreigners to make mistakes in translating Chinese poetry. Early translators paid more attention to expressiveness and chose to ignore 
those intractable cultural and linguistic difficulties while later translators emphasized more faithfulness to the original[11]."

In the long practice and research in China, translators put forward such principles in poetry translation as Xu Yuanchong's three beauties (the beauty of meaning, the beauty of form, the beauty of sound), three perfections (simplification, equalization, deepening of meaning), three similarities (the similarity of form, the similarity of spirit and the similarity of meaning) and Wang Rongpei's "conveying the meaning in its full flavor". Translating form, sound and meaning in Chinese poetry remains a much discussed topic. It is argued that poetry can only be translated in the form of poetry. Only in this way can the version be faithful to the original poetry and convey the same artistic beauty, rhythm and various forms as the original.[12] When translating classical Chinese poetry, translators are supposed to follow rules of composing English metrical poetry, use fluent modern English and highlight Chinese poetic characteristics in English versions as well. If the original poetry is in rhyme form, versions should also use rhymes [13].

Studies on Shijing translation concern deeper issues, including translators' motives, overt and covert influencing factors manipulating translating work and purposeful act in translating, etc. Researchers apply translation theory to academic research. For example, Research on English Translation of Chinese Poetry: James Legge, Herbert Giles, Arthur Waley and Ezra Pound (2012) expounds the translating work of the four influential translators, their translating strategies, motives and western reception of their renditions. The author made an inspirational and incisive study on Shijing translation by James Legge, Arthur Waley and Ezra Pound and investigated how translators understand and deal with images containing rich cultural information.[14] This book exerts a great influence on studies in this area for its rich content, valuable first-hand sources and great insight. Ruist Character in James Legge's English Version of Shijing (2005) researched into the influence of Legge'sruism (Confucianism) on his translation, concluding that Legge's translation was influenced by his ruist thinking.[15] Two Difficulties in Shijing Translation (2006) pointed out interpretation of words and translational motives are two factors determining the quality of translation.[16] Li's dissertation, Studies on English Translation of Shijing (2007), expounded the source text and referential system of English versions of Shijing, explored the historical motives in translating Shijing in early times and its dissemination and made some comparisons of different versions and translators such as James Legge, William Jennings, C.F.R. Allen, Arthur Waley, Ezra Pound and drew a conclusion that James Legge's translation was characterized by "ruism", William Jennings' by both "ruism" and "academics", C.F.R. Allen's by cultural manipulation, Arthur Waley's by deviation from ruism and Ezra Pound's by imagism.[17] These studies cover a wide range from the micro reflection to the macro analysis, from translated works to translators, from linguistic studies to cultures, sociology and poetics, from internal studies to external investigation, which has greatly promoted studies in this field.

Compared with the above research, Research on English Translation of Shijing(2013) makes a micro investigation, starting with the relationship between literary translation, translation of Chinese classics, especially Shijing, followed by a detailed analysis of English version of Shijing from the perspectives of literary studies, vernaculars and cultural studies. Vernaculars are the focus of the book. [18] With many concrete examples, readers can get a clear idea of the history of Shijing translation.

In this period, research was not confined in the simple introduction of translations and translators. Chinese scholars and translators came to realize their responsibility in 
translating and studying classical Chinese poetry. In the experimentation, they took some serious thinking about translating nature and content and their interest extended to important related research objects in translatology involving translating choices made by translators, translation standards, transferring cultures, translation purposes and receptions of target readers in alien cultures. The methodology covered traditional textual analysis and modern historiographical analysis, cultural phenomenology analysis and poetics analysis. Scholars consciously take examples from Shijing when discussing translating topics and many theoretical translation subjects get well justified in the translation of Shijing. Yet it is far from enough to construct Shijingtranslatology for its lack of strict terminology, rational discourse norms, objective theory framework, comprehensive analysis methodology and stable explanatory power, which, in Zhu Chunshen's opinion, are the prerequisites of constructing a sound theory.[19]It was during this time that western translation theories and thoughts poured into China and were readily accepted by academic circles. When Chinese poetry translation theory is not constructed, western translation theories are employed to clarify problems in Chinese poetry translation. Scholars expect that in practice they can come up with a distinctive translating methodology and sets of rules to produce a distinctive theory of Chinese poetry translation.

In this phase, scholars get to realize the role culture has played in translation but it is shadowed by the larger purpose for the Chinese Shijing translatology.

\section{BigTransition of ShijingTranslation Studies:Multilaye red, Multi-perspective, Interdisciplinary and Cross-cultural Studies}

The advancement of studies on Shijing translation fascinates a growing number of scholars from various disciplines. Classicists, political reformers, literary men, historians, linguists, archeologists and naturalists are able to find valuable sources they need in Shijing. It is this comprehensive, multi-layered, multi-perspective, interdisciplinary and cross-cultural research that endows Shijing with new academic vitality and lasting charm in this new era. Culture finds its way to the core of research on Shijing translation.

\section{Multi-pe rspective and Interdisciplinary Cultural Studies on Shijing}

Modern studies on Shijing are not limited in the literary area. In its long translation history, academic orientations have covered a wide range of translators, historical backgrounds of different renditions, the formation of particular English versions in specific times, and social, historical and cultural backgrounds. Recent trend concerns cross-cultural studies from multi-layered, multi-dimensional and multidisciplinary perspectives.

The long translation history of Shijing is a perfect topic for studies on historical culture. Bridging the East and the West: A Research on the Scottish Sinologist James Legge(1815-1897) by Yue Feng(2003) took James Legge as his study object, studying the history of Legge's work of translating Chinese classics, Shijing being its fourth volume. The author made an insightful study on the translator's motives, values and attitudes towards Chinese classics and working conditions.[20] This study aims to investigate how James Legge bridged the East and the West, not a treatise on Shijing translation. Jiang Yan specialized in studies on James Legge's translation of Shijing(2010). Her dissertation revolves around three versions of Shijing by James Legge and investigates Legge's translating strategies, purposes, influencing factors and translating thoughts.[21]This is a thorough investigation for James Legge's work 
on Shijing. The author furthered her study in James Legge's Translation of Shijing and Interpretation of Confucianism (2013), in which she employed power relations translation theory to analyze different versions by Legge and explored historical and cultural contexts in which these versions came into being. [22] The researcher aimed to clarify the gradual transition of the translator's thoughts reflected in different versions.

Shijing, as an important means of bridging the eastern and western cultures, also becomes a fascinating research object for comparative literature. Cross-cultural Hermeneutics: Studies on James Legge's English Translations of the Shijing (2013) combines close reading, interdisciplinarystudies of translation, hermeneutics and comparative literature, logical argument, comparison and statistics, etc. to interpret eastern and western hermeneutic traditions, different translating thoughts shown in versions, cultures, literature and imagism.[23]Another dissertation, James Legge's Translation and Hermeneutics of Shijing: a Case Study of Two Versions of Shijing in The Chinese Classics(2011), set in the thriving British sinology in the $19^{\text {th }}$ century, compares and analyzes two different versions of Shijing in the Chinese Classics to elucidate some changes in Legge's ideologies and translating strategies in his two translating undertakings.[24]It unfolds the evolution of renditions from critical rewriting tradition to literary reinterpretation.

Researchers find rich social and historical information for anthropological studies. This kind of research originated from Marcel Granet's influential book, Fetes et Chansons Anciennes de la Chine (Festivals and Songs in Ancient China, 1919) which uncovered an untouched area of anthropological research on Shijing.[25]The Application of Cultural Anthropology on the Book of Poetry (2007) analyzes Granet's anthropological thinking by closely reading his works.[26]Translation,Biography, Intercourse:Studieson Arthur Waley'sSinological Strategies (2010) explores Arthur Waley's anthropological ideology. With the aid of theoretical findings in anthropology, she found that Waley broke through James Legge's religious ideology and that he restored the true anthropological feature of Shijing when reorganizing poems in his Shijingtranslation.[27]Anthropological Exploration in Arthur Waley'shijing Translation(2012) also explores Waley's thoughts of anthropological culture in his paper.[28]

Shijingtranslation conveys how translators understand ancient Chinese society and its culture. Social Pictures of Xia,Shang and Zhou Dynasties in James Legge's Book of Poetry (2009) finds, by studying religion, politics and marriage in the rendition, that Legge depicts social landscape in Xia, Shang and Zhou Dynasties. Yet, some social information has been misinterpreted due to Legge's misunderstanding of the original Shijing.[29]Studies on Ancient Chinese Society in Shijing Translation(2014) investigates inferiority of women in their social identity and family life in sharp contrast to superiority of men for their hegemony and absolute power and prestige. [30] In translating the Chinese Classics, Legge placed Chinese ancient religious belief in the framework of Christian theology.

\section{Studies of Shijing Translation Influenced by Western Translation Theory}

In the late 1980s, foreign translation theories poured into Chinese translation academic circle, which provides new research perspectives and horizons for translation studies and important means to studies on Shijingtranslation. Western theories such as post-colonial translatology, deconstruction translatology, corpus translatology, skopos theory and polysystem theory get incorporated with Chinese translation studies and bring out more potential research objects for interpreting 
Shijing.

The introduction of modern translation theories endows scholars with more perspectives and materials. Gains and Losses of New Methodology in Western Studies on Shijing(2000) expounds new methodologies in foreign research onShijing from perspectives of traditional hermeneutics, modern reception aesthetics, literary ontology, linguistics, psychoanalysis and cultural anthropology.[31]These fields greatly enrich Shijng studies. Studies on Shijing in English World (2006) introduces new findings of Shijing studies in western countries which benefit tremendously from western theories in linguistics, cultural anthropology and imagism. [32]

Western theories such as translator's subjectivity, corpus, translation manipulation, western aesthetics, post-colonialism, constructionism, hermeneutics are applied to new interpretation of Shijing, improving new studies on Shijing and becoming new academic orientations in this field. Such researches include StudiesontheEnglishVersionsof. TheBookofsongsFromPerspectiveoftheTranslator's Subjectivity (2011), On the Translation of Regional Songs of Book of Poetry: from the Perspective of Poetics in Andre Lefevere's Manipulation Theory (2011), A Comparative Study on English Translation on Shijing from an Aesthetic Perspective: Exampled by the Versions of Legge and Xu Yuanchong (2012)Creative Treason in the English Versions of "Zhong Si" from the Perspective of Deconstruction Translation Theory (2013). [33, 34, 35, 36]

\section{Reflection and Prospect of Studies on English Versions of Shijing}

Despite great achievements studies on Shijing translation in mainland China, some problems exist in domestic studies. "Though current studies cover a great number of translators, there lack more insightful and deeper studies on individuals; studies on versions cover miscellaneous renditions yet lack a depiction of the whole picture of the Shijing translation; studies on its dissemination need to put more emphasis on its causes and its true nature."[37]As far as domestic studies are concerned, many studies focus on some translator or compare the same version by various translators, which fragments the history of Shijing translation and prevents readers from picturing a complete and comprehensive history of Shijing translation. Besides, studies on popular translators such as James Legge, Arthur Waley or Ezra Pound account for a large proportion while there lacks enough research on other translators who help shape the history. Furthermore, despite much research on translation strategies, translators and comparisons of differing versions of Shijing, they are in want of deep investigation of political, cultural, religious and social factors dominating Shijing translation, making it hard to interpret dynamic evolution and changes in translation thoughts and strategies.

Current academic studies break barriers of various disciplines. Different disciplines and fields often collide and overlap, facilitating the emergence of interdisciplinary and multidimensional academic research. New historical records and research objects have been uncovered. For instance, Inspiration of Overseas Research on Shijing (2006) proposes the global vision of Shijing discipline. Zheng Zhongqiu has found that far before James Legge, English-Chinese Dictionary edited by Robert Morrison quoted many lines from Shijing, which carried on the tentative work of William Jones and bridged professional translation and research of James Legge. This is a new finding in British research on Shijing translation.[38] 


\section{Conclusion}

Shijing, as a Chinese poetry classic, shines brightly in English world as well and serves as a popular topic of academic research. Scholars experience academic development from the early topic "who translates and what to translate" to "how to translate" further to "why translate", signifying researchers' further understanding of Shijing translation. However, as a newly-emerging research object, there still exist some problems. Some research puts more emphasis on language than culture, more on translators than versions, more on literariness than history, more on prescriptive translation methods than descriptive translation methods. These problems will get improved with research further progressing. In addition, new historical materials, perspectives and theories will bring much potential to research on Shijing translation. Multi-dimensional cross-cultural disciplines are bound to further future research on Shijing.

\section{References}

[1] Fan Cunzhong, Chinese Culture in Britain during the Period of Enlightenment, Shanghai: Shanghai Foreign Language Education Press, 1993.

[2] Xu Yuanchong, The Book of Poetry,Beijing: China Literature Press, 1993.

[3] Xu Yuanchong, On Chinese Verse in English Rhyme: From The Book of Poetry to The Romance of The Western Bower, Beijing: Peking University Press, 1992.

[4] Song Bainian, Classical Chinese Literature outside China, Beijing: Beijing Languages University Press, 1994.

[5] Hu xianyuan, Shijing: Songs from Ancient Chinese, Kunming: Yunnan People's Publishing House, 1998.

[6] Zhou Faxiang, The Spread and Research on Shijing in the West, Literary Review, No. 6, pp70-81, 1993.

[7] Wang Lina, Shijing outside China, Shijing Studies International Forum(1993), pp66-80, 1993.

[8] Wang Lina, The Formation and Evolution of Studies on Shijing in the West, Journal of Hebei Teachers College(Social Science Edition), No. 4, pp47-52, 1996.

[9] Shan Qing, Transmission of Shijing to the West and Its Translation, Book City, No.2, pp25-26, 1995.

[10]Xia Chuancai, A Brief Account of Studies on Shijing outside China, Journal of Hebei Teachers College (Social Science Edition), No. 2, pp70-77, 1997.

[11]LüShuxiang, A Comparative Study on English Translation of Old Gems, Shanghai: Shanghai Foreign Language Education Press, 1980.

[12]Wang Rongpei, Translation and Culture, Journal of Shijing Studies, No.1, pp341-350, 2002.

[13]Wang Rongpei, English Translation of The Book of Songs, China Translators Journal, No. 6, pp33-35, 2007.

[14]Wu Fusheng, Research on English Translation of Chinese Poetry: James Legge, Herbert Giles, Arthur Waley and Ezra Pound, Beijing: Academy Press, 2012. 
[15]Li Yuliang, Ruist Character in James Legge's English Version of Shijing, Foreign Language Education, Vol.26, No.5, pp63-66, 2005.

[16]Li Yuliang, Two Difficulties in Shijing Translation, The Seventh Symposium of English-Chinese Comparative Studies in China, 2006.

[17]Li Yuliang, Studies on English Translation of Shijing, Jinan: Qilu Press, 2007.

[18]Liang Gaoyan, Textual Research of English Translation of the Animal Names in Regional Songs from the Book of Poetry - Based on the Textual Research of “骐雷” (qizhu) in the Poem of the Small Chariot, Journal of North University of China (Social Science),No. 129, No. 3, pp61-65, 2013.

[19]Zhu Chunshen, Step Out of Erroneous Zones Towards the World Perspective, Chinese Translators Journal, No.1, pp2-9, 2000.

[20]Yue Feng, Bridging the East and the West: A Research on the Scottish Sinologist James Legge(1815-1897), Fujian Normal University, 2003.

[21]Jiang Yan, James Legge's Translation ofShijing,Shandong Univeristy, 2010.

[22]Jiang Yan,James Legge's Views on the Religious Dimensions of Confucianism, Journal of Shandong University (Philosophy and Social Sciences), No.1, pp125-133, 2013.

[23]Shen Lan, Cross-cultural Hermeneutics: Studies on James Legge's English Translations of the Shijing,Suzhou University, 2013.

[24]Liu Fang James Legge's Translation and Hermeneutics of Shijing: a Case Study of Two Versions of Shijing in The Chinese Classics, Peking University, 2011.

[25]M. Granet, Zhao Bingxiang (Tr.), Fetes et Chansons Anciennes de la Chine, Guilin: Guangxi Normal University Press, 2005.

[26]Wu Jieping, The Application of Cultural Anthropology on the Book of Poetry, Study of Ethics of Guangxi, No. 1, pp38-44, 2007.

[27]Ji Ailian,Translation, Biography, Intercourse: Studies on Arthur Waley'sSinological Strategies,Fujian Normal University, 2010.

[28]Li Yuliang, Anthropological Exploration in Arthur Waley'sShijing Translation, Journal of Qingdao University of Science and Technology(Social Sciences), Vol. 28, No. 1, pp104-109, 2012.

[29]Jiang Yan, Social Pictures of Xia, Shang and Zhou Dynasties in James Legge's Book of Poetry, Qilu Journal, No. 213, pp61-65, 2009.

[30]Du Yuan and Chen Jirong, Studies on Ancient Chinese Society in Shijing Translation, Journal of Luoyang Normal University, Vol.33, No.10, pp91-94, 2014.

[31]Xia Chuancai, Merits and Demerits of New Overseas Methodology of Classic of Poetry, Literary Heritage, No.6, pp4-19, 2000.

[32]Wu Jieping, Research on The Book of Poetry in English World, Journal of Yibin University, No.9, pp89-92, 2006.

[33]Jin Ying, Studies on the English Versions of The Book of songs From Perspective of the Translator's Subjectivity, Hebei Normal University, 2011. 
[34]Tan Jingwen, On the Translation of Regional Songs of Book of Poetry: from the Perspective of Poetics in Andre Lefevere's Manipulation Theory, Central South University, 2011.

[35] Hu Keli,A Comparative Study on English Translation on Shijing from an Aesthetic Perspective --- Exampled by the Versions of Legge and Xu Yuanchong, Central South University, 2012.

[36]Wang Xiaoling, Creative Treason in the English Versions of "Zhong Si" from the Perspective of Deconstruction Translation Theory, Foreign Language and Literature, No. S1, pp135-138, 2013.

[37]Wen Jun and HaoShujie, Domestic Studies of Shijing Translation in Twenty Years, Foreign Language and Literature Studies, No. 2, pp93-98, 2011.

[38]Zheng Zhongqiu, The Translation of Shijing in Robert Morrison's A Dictionary of the Chinese Language, Journal of Hebei United University (Social Science Edition), Vol. 13, No.6, pp 159-162, 2013. 